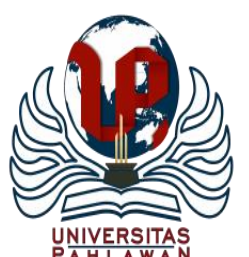

Jurnal Basicedu Volume 5 Nomor 1 Tahun 2021 Halaman 188-194

JURNAL BASICEDU

Research \& Learning in Elementary Education

https://jbasic.org/index.php/basicedu

\title{
Implementasi Pembelajaran Daring bagi Siswa Tunanetra di Sekolah Dasar
}

\author{
Hermanto $^{1}$, Asep Supena ${ }^{2}$ \\ Program Studi Doktor Pendidikan Dasar Pascasarjana, Universitas Negeri Jakarta ${ }^{1}$ \\ Program Pascasarjana, Fakultas Ilmu Pendidikan, Universitas Negeri Jakarta ${ }^{2}$ \\ Email: pbmanto92@gmail.com ${ }^{1}$ supena2007@yahoo.com $^{2}$
}

\begin{abstract}
Abstrak
Penelitian ini bertujuan untuk pertama mengetahui pelaksanaan pembelajaran secara daring bagi siswa tunanetra di SDN Inklusif Sangiang Pulau, kedua mengetahui peran guru dan orang tua dalam pembelajaran daring bagi siswa tunanetra, ketiga mengetahui solusi yang dilakukan oleh guru dan orang tua dalam pembelajaran daring. Metode penelitian yang digunakan dalam penelitian adalah metode kualitatif deskriptif dengan sumber data diperoleh dari kepala sekolah, guru dan peserta didik. Analisis data menggunakan model interaktif meliputi pengumpulan data, reduksi data, penyajian data, hingga penarikan kesimpulan. Selanjutnya data dari hasil observasi, wawancara dan dokumentasi dilakukan triangulasi. Temuan dalam penelitian ini adalah guru melaksanakan pembelajaran daring menggunakan media WhatsApp dengan membuat video dan rekaman untuk menunjang pembelajaran siswa tunanetra. Guru dan orang tua siswa membangun komunikasi dan kolaborasi dalam mendukung pembelajaran siswa tunanetra serta kerjasama antara guru, orang tua dan siswa dalam pembelajaran daring tersebut.
\end{abstract}

Kata kunci: pendidikan inklusif, tunanetra, pembelajaran daring

\section{Abstract}

This study aims to first determine the implementation of online learning for visual impairment students at SDN Inclusive Sangiang Island, second to know the role of teachers and parents in online learning for visual impairment students, third to find out the solutions made by teachers and parents in online learning. The research method used in the research is a descriptive qualitative method with data sources obtained from school principals, teachers, and students. Data analysis using interactive models include data collection, data reduction, data presentation, to concluding. Then the data from the results of observations, interviews, and documentation will be triangulated. The findings in this study are that the teacher implements online learning using WhatsApp media by making videos and recordings to support the learning of visual impairment students. Teachers and parents of students build communication and collaboration in supporting the learning of blind students as well as collaboration between teachers, parents and students in online learning.

Keywords: inclusive educational, visual impairment, online learning

Copyright (c) 2021 Hermanto, Asep Supena

$\bowtie$ Corresponding author :

Address : Rawamangun Jakarta Timur

Email : pbmanto92@gmail.com

ISSN 2580-3735 (Media Cetak)

Phone : 085237919341

DOI : https://doi.org/10.31004/basicedu.v5i1.635

ISSN 2580-1147 (Media Online) 


\section{PENDAHULUAN}

Pendidikan sangatlah penting dalam mempengaruhi perkembangan manusia untuk seluruh aspek kepribadian dan kehidupannya. Karena pada dasarnya pendidikan adalah hak semua warga negara yang cita-citanya memanusiakan manusia, termasuk anak-anak berkebutuhan khusus. Selain itu pendidikan memiliki pengaruh yang dinamis dalam menyiapkan kehidupan manusia di masa depan. Pendidikan juga dapat mengembangkan berbagai potensi yang dimiliki secara optimal, yaitu pengembangan potensi individu dalam aspek fisik, intelektual, emosional, sosial dan spiritual, sesuai dengan tahap perkembangan serta karakteristik lingkungan fisik dan lingkungan sosial budaya dimana dia hidup (Saputri \& Wangid, 2013).

Menurut

UNESCO

(2015)

merekomendasikan agar negara-negara berkembang menerapkan pendidikan inklusif sebagai alternatif yang hemat biaya untuk mendidik anak-anak penyandang disabilitas. Hasilnya, minat terhadap pendidikan inklusif semakin meningkat (Lamichane, 2015). Sementara di Indonesia harapan untuk peningkatan pendidikan inklusif mengalami perkembangan yang cukup pesat. Saat ini tercatat ada lebih dari 1000 sekolah secara nasional, yang dinyatakan sebagai sekolah inklusif, yang tersebar di berbagai wilayah, dengan jenjang sekolah yang bervariasi dari mulai TK, SD, SMP, dan SMA/SMK. Di Provinsi Jawa Barat ada lebih kurang 172 sekolah inklusif, sedangkan di DKI Jakarta tercatat ada kurang lebih 164 sekolah. Perkembangan sekolah inklusif juga menunjukkan kondisi yang menggembirakan di sejumlah provinsi lainnya misalnya Jawa Tengah, Yogyakarta, Jawa Timur, Sumatera Selatan, Sumatera Barat, Sulawesi Selatan, Aceh, NTB, juga Kalimantan Tengah dan Maluku Utara (Supena, 2012).

Berdasarkan pendapat tersebut anak yang memiliki kebutuhan khusus pun memiliki hak yang sama dalam memperoleh pendidikan. Oleh karena itu di dalam dunia pendidikan, konsep perbedaan atau kebhinekaan adalah terkait dengan individual differences sedangkan konsep kesamaan adalah kesamaan dalam misi yang diemban oleh manusia dalam kehidupannya (Kurniawan, 2015). Perbedaan dapat bersifat vertikal dan dapat pula bersifat horizontal. Perbedaan vertikal menunjuk pada intelegensi, ketajaman sensoris, kekuatan fisik, kematangan emosi, dan ketajaman intuisi.

Perbedaan horizontal menunjuk pada ras, suku bangsa, agama, adat istiadat, dan bahasa yang semuanya memiliki posisi yang setara sehingga tidak ada yang lebih rendah atau lebih tinggi. Dengan adanya perbedaan tersebut maka dimungkinkan manusia dapat saling berhubungan dalam rangka saling membutuhkan. Kesamaan menunjuk pada ketunggalan tugas semua manusia dalam hidupnya, yaitu semata-mata mengabdi kepada Tuhan Yang Maha Esa.

Untuk mengimplementasi tersebut pemerintah membuat sekolah inklusif yang bertujuan semua anak memiliki hak sama dalam memperoleh pendidikan. Adapun filosofi yang mendasari pendidikan inklusif adalah keyakinan bahwa setiap anak, baik karena gangguan perkembangan fisik (mental) maupun cerdas/bakat istimewa berhak untuk memperoleh pendidikan seperti layaknya anak-anak "normal" lainnya dalam lingkungan yang sama (Education for All). 
Sedangkan dalam ensiklopedi online Wikipedia disebutkan bahwa yang dimaksud dengan pendidikan inklusif yaitu pendidikan yang memasukkan peserta didik berkebutuhan khusus untuk bersama-sama dengan peserta didik normal lainnya.

Pada lembaga pendidikan inklusif, perbedaan individual peserta didik sangat diperhatikan, sehingga anak berkebutuhan khusus maupun anak normal dapat mengembangkan potensi yang dimiliki secara optimal sesuai dengan kondisi masing-masing, hal ini menyebabkan adanya penyesuaian yang harus dilakukan oleh guru dalam proses pembelajaran. Di tengah situasi pandemi Covid-19 ini juga menuntut guru, orang tua, dan siswa dalam mensukseskan proses pembelajaran yang dilaksanakan. Untuk itu peneliti tertarik untuk meneliti tentang "Implementasi Pembelajaran secara Daring pada Siswa Tunanetra atau dengan Gangguan Penglihatan". Dengan fokus penelitian yang pertama pelaksanaan pembelajaran daring bagi siswa tunanetra, kedua peran guru dan orang tua dalam pembelajaran siswa secara online, ketiga adalah solusi yang dilakukan oleh guru dan orang tua.

\section{METODE}

Penelitian ini menggunakan pendekatan kualitatif dengan metode deskriptif. Penelitian kualitatif dengan metode deskriptif adalah metode yang menjelaskan atau mendeskripsikan suatu fakta, data, dan objek penelitian secara sistematis dan sesuai dengan situasi alamiah. Terkait hal yang diteliti, hasil penelitian lebih menekankan pada makna dari pada hasil, dan hasil penelitian tidak mengikat serta dapat berubah sesuai dengan kondisi yang dihadapi di lapangan penelitian dan diinterpretasikan dan dituliskan dalam bentuk katakata atau deskriptif berdasarkan fakta di lapangan (Anggito \& Setiawan, 2018).

Penelitian ini dilaksanakan di SDN Inklusif Pulau Sangiang, Kecamatan Wera, Kabupaten Bima, Nusa Tenggara Barat dengan sumber data penelitian yaitu informan (guru, orang tua, dan siswa). Peneliti berperan sebagai human instrument (peneliti melakukan penelitiannya sendiri). Pengambilan sampel dan sumber data dilakukan secara purposive sampling (pengambilan sampel berdasarkan atas sebuah pertimbangan yang berfokus pada tujuan tertentu dan peneliti sudah menentukan sebuah kriteria pada pengambilan sampelnya), pengambilan sampel berdasarkan kebutuhan dan sesuai dengan topik penelitian. Teknik pengumpulan data menggunakan wawancara, observasi, dan dokumentasi (Moleong, 2017). Analisis data bersifat kualitatif, dengan menggunakan model Milles \& Huberman yaitu reduksi data, penyajian data dan kesimpulan atau verifikasi (Miles \& Huberman, 2013). Adapun teknik pemeriksaan keabsahan data yang digunakan adalah: triangulasi data, meningkatkan ketekunan, dan menggunakan bahan referensi (Sugiyono, 2018).

\section{HASIL DAN PEMBAHASAN}

Dari hasil penelitian didapatkan dari tiga fokus penelitian utama yang dapat dideskripsikan dalam penelitian ini berdasarkan hasil wawancara, observasi dan dokumentasi serta diperkuat dengan kajian teori dari berbagai referensi. Tiga fokus penelitian yang akan dideskripsikan dalam hasil 
dan pembahasan penelitian tersebut yaitu; pertama pelaksanaan pembelajaran daring bagi siswa tunanetra di SDN Inklusif Sangiang Pulau, kedua peran guru dan orang tua dalam pembelajaran siswa secara daring, ketiga adalah solusi yang dilakukan oleh guru dan orang tua.

\section{Pelaksanaan Pembelajaran Daring bagi Siswa}

\section{Tunanetra}

Anak-anak dengan gangguan penglihatan mengalami kesulitan dalam menyelesaikan tugastugas visual, tetapi mereka dapat belajar melalui indra visual dengan menggunakan berbagai teknologi dan teknik pengajaran khusus (Kirk et al., 2009). Untuk itu berdasarkan hasil wawancara dengan informan guru SDN Sangiang pulau bahwa: proses pembelajaran daring bagi siswa tunanetra berjalan dengan baik apabila menggunakan media pembelajaran yang mendukung dalam kesempatan tersebut guru dalam memberikan materi pelajaran pada siswa baik melalui media WhatsApp grup atau melalui WhatsApp pribadi harus didukung oleh video pembelajaran yang dibuat oleh guru sehingga siswa dan dibantu oleh orang tuanya dapat melihat secara berulang-ulang materi yang sudah diberikan.

\section{Hasil wawawancara sebagai berikut :}

"Menurut saya proses pembelajaran daring untuk siswa tunanetra berjalan dengan baik dan efisien dengan menggunakan media pembelajaran yang mendukung. Misalnya dalam kesempatan tersebut saya sebagai guru ketika memberikan materi pelajaran pada siswa baik melalui media WhatsApp grup atau melalui WhatsApp pribadi saya selalu menggunakan video yang saya desain terlebih dahulu baru dikirim ke siswa melalui WhatsApp (W1.G.12.09.2020).”
Dan selanjutnya wawancara yang dilakukan melalui media telepon adalah :

\begin{abstract}
"Saya dalam melaksanakan pembelajaran daring pada siswa tunanetra pada sekolah inklusif selalu membedakan materi terutama untuk kebutuhan khusus dengan anak-anak normal lainnya. Anak-anak tunanetra kadang saya merekam materi dan membuatkan PowerPoint dan video agar mereka memahami materi yang di ajarkan. Selain dari itu membangun komunikasi dan kolaborasi dengan orang tua siswa agar membantu proses belajar anak-anaknya di rumah dengan cara seperti itu pembelajaran dan materi yang disampaikan dapat dipahami oleh siswa, tutupnya (Dok.G.23.09.2020). "
\end{abstract}

Berdasarkan wawancara tersebut guru dalam melaksanakan pembelajaran daring pada siswa tunanetra atau gangguan penglihatan pada sekolah inklusif melakukan analisis kebutuhan terutama berkaitan dengan materi yang akan diajarkan, pada anak-anak berkebutuhan khusus atau tunanetra guru menyiapkan materi yang sudah di rekam dengan menggunakan aplikasi rekaman dan menggunakan video serta PowerPoint untuk membantu siswa memahami materi yang akan diberikan. Selain dari membedakan materi yang akan disampaikan kepada siswa tunanetra guru membangun komunikasi dan kolaborasi dengan orang tua siswa agar membantu siswa dalam proses belajarnya di rumah dengan cara seperti itu pembelajaran dapat dipahami oleh siswa dan bermakna.

\section{Peran Guru dan Orang Tua dalam Pembelajaran Siswa secara Daring}

Peran guru dan orang tua sangat dibutuhkan dalam proses pembelajaran daring bagi siswa tunanetra, bagaimana tidak siswa yang terganggu dengan indra penglihatannya ini sangat 
membutuhkan peran guru dan orang tua dalam pembelajaran, apalagi dengan melalui pembelajaran daring yang didalamnya terdapat banyak kendala-kendala misalnya kendala jaringan, seorang anak tidak bisa menggunakan atau mengoperasikan handphone, dan laptop untuk menerima materi dari gurunya.

Berdasarkan wawancara dengan informan guru sebagai berikut:

\begin{abstract}
"Menurut saya peran guru dalam membimbing siswa dalam pembelajaran daring sangat penting, ada beberapa hal yang saya lakukan untuk membantu siswa dalam proses pembelajaran secara daring, yang pertama saya akan membuat materi yang mudah dipahami oleh siswa, kedua saya akan menggunakan media untuk menunjang proses pembelajaran, dan melakukan monitoring dengan siswa melalui orang tua siswa dengan menggunakan telepon seluler, selanjutnya tetap mengingatkan siswa untuk tetap menjaga kesehatannya, tutupnya (W2.G.13.09.2020)."
\end{abstract}

Selanjutnya wawancara dengan salah satu informan orang tua siswa yaitu:

"Hal yang paling utama yang saya lakukan adalah selalu berada di sekitar anakku ketika sedang proses belejar mengajar secara langsung, kemudian membantu mereka memahami kesulitan-kesulitan dalam proses belajarnya serta menyiapkan beberapa kebutuhan anak-anak untuk belajar mengajar, misalnya handphone, buku catatan dan lain sebagainya, tutupnya" (W1.OT.15.09.2020).

Dari beberapa hasil wawancara dengan informan baik dengan guru maupun orang tua siswa dapat dijelaskan bahwa guru dan orang tua dalam proses pembelajaran daring bagi siswa tunanetra sangat dibutuhkan, karena siswa dengan keterbatasan penglihatan tersebut bisa memahami dan menelaah materi yang diajarkan oleh guru. Salah satu peran guru dan orang tua yang sudah dijelaskan dalam hasil wawancara tersebut adalah, guru membuat materi yang mudah dimengerti oleh siswa sedemikian rupa, serta melakukan monitoring kepada orang tua siswa agar mengingatkan kembali kepada siswa materi yang sudah diberikan.

Kemudian peran orang tua siswa dalam pembelajaran daring ini, para orang tua selalu ada di samping siswa ketika proses belajar sudah dilaksanakan, dan orang tua membantu mempersiapkan media penunjang pembelajaran bagi anak-anaknya. Oleh karena itu penting untuk diketahui bahwa peran orang tua dalam pembelajaran daring sangat dibutuhkan bagi siswa mengingat banyak hambatan-hambatan yang terjadi di dalamnya dengan keberadaan orang tua siswa kesulitan belajar bagi siswa bisa diminimalisir.

\section{Solusi yang Dilakukan oleh Guru dan Orang} Tua

Salah satu bentuk layanan belajar bagi anak berkebutuhan khusus adalah pemberian treatment agar kesulitan dan hambatan belajar yang dialami siswa berkebutuhan khusus dapat diatasi. Harapannya adalah melalui layanan belajar yang tepat siswa yang berkebutuhan khusus dapat mengembangkan secara optimal potensi yang ada pada dirinya. Terdapat berbagai macam treatment yang dapat dilakukan untuk mengatasi kesulitan belajar pada anak tunanetra, salah satunya adalah dengan penggunaan media sebagai alat bantu belajar. Peranan media sangat penting dalam pembelajaran mengingat media dapat bermanfaat untuk membantu menyampaikan informasi dari pembelajaran kepada subjek ajar secara efektif. 
193 Implementasi Pembelajaran Daring Bagi Siswa Tunanetra di Sekolah Dasar- Hermanto, Asep Supena DOI : https://doi.org/10.31004/basicedu.v5i1.635

Berdasarkan wawancara dengan guru dan orang tua siswa menyatakan :

\begin{abstract}
"Menurut mereka salah satu solusi yang dilakukan untuk membantu proses belajar terhadap siswa tunanetra adalah menggunakan media entahkah handphone, video, buku dan bahan untuk mendukung proses belajar tersebut" (W3.G.OT.23.09.2020).
\end{abstract}

Ditengah keterbatasan dan kemampuan melihat secara jelas siswa sangat memerlukan media dalam menunjang proses belajar mengajar apalagi dilakukan secara daring, ini akan membantu siswa dalam memahami yang diajarkan oleh gurunya. Hal ini selaras dengan pendapat Hamalik (2012) menjelaskan secara rinci tentang penggunaan media, yaitu: pemakaian media pembelajaran dalam proses belajar mengajar dapat membangkitkan keinginan dan minat yang baru, membangkitkan motivasi, dan ransangan kegiatan belajar, dan bahkan membawa pengaruh-pengaruh psikologis terhadap siswa. Media pembelajaran juga dapat membantu siswa meningkatkan pemahaman, menyajikan data dengan menarik dan terpercaya, memudahkan penafsiran data, dan mendapatkan informasi.

Dari penjelasan tersebut diatas sangat penting penggunaan media bagi pembelajaran siswa tunanetra, tetapi kenyataan di lapangan jarang menggunakan media dalam proses pembelajaran bagi anak tunanetra. Karena selain dari keterbatasan alat juga keterbatasan waktu mengajar siswa. Dan ditambah lagi siswa tunanetra harus diorientasi dan mobiltias dalam proses pembelajaran, ditambah lagi dengan keterbatasan guru dalam baca tulis brailed. Oleh karena demikian solusinya yaitu dengan memaksimalkan penggunaan media sebagai penunjang proses pembelajaran.

\section{SIMPULAN}

Berdasarkan hasil penelitian ini dapat disimpulkan bahwa anak-anak dengan gangguan penglihatan mengalami kesulitan dalam menyelesaikan tugas-tugas visual, tetapi mereka dapat belajar melalui indra visual dengan menggunakan berbagai teknologi dan teknik pengajaran khusus. Proses pembelajaran secara daring dapat dilakukan secara baik dan efisien apabila pelaksanaan tersebut dengan menggunakan media pembelajaran dengan pembuatan video, rekaman, dan PowerPoint sehingga membantu siswa tunanetra dalam memahami pelajaran yang diberikan. Selain dari pelaksanaan pembelajaran tersebut peran guru dan orang tua dalam pembelajaran daring sangat diperlukan karena berbagai hambatan dan masalah yang sering muncul ketika proses pembelajaran online dilakukan ditambah lagi dengan siswa yang kurang memahami penggunaan media tersebut.

Oleh karena itu solusi yang dilakukan oleh guru dan orang tua dalam penelitian ini adalah guru dan orang tetap membangun komunikasi dan kolaborasi sehingga dalam proses pembelajaran keterlibatan mereka secara penuh untuk memahamkan siswa dalam menerima materi dapat dicapai kemudian guru dan siswa juga memaksimalkan penggunaan media sebagai penunjang dalam pembelajaran daring.

\section{DAFTAR PUSTAKA}

Anggito, A., \& Setiawan, J. (2018). Metodologi penelitian kualitatif. Sukabumi: CV Jejak 
194 Implementasi Pembelajaran Daring Bagi Siswa Tunanetra di Sekolah Dasar- Hermanto, Asep Supena DOI : https://doi.org/10.31004/basicedu.v5i1.635

(Jejak Publisher).

Asep Supena (2012). Model Pendidikan Inklusif Untuk Siswa Tunanetra. JURNAL PENDIDIKAN LUAR BIASA, APRIL 2012, VOLUME 08 NOMOR 1; 25-50

Aprilia Eki Saputri, Muhammad Nur Wangid (2013). Pembelajaran Sains SD Untuk Siswa Tunanetra di SLB-A Yaketunis. Jurnal Prima Edukasia, Volume 1 Nomor 2, 2013

Dwi yanti Fiona putri (2012). Proses Pembelajaran Pada Sekolah Dasar Inklusi. E-JUPEKhu (Jurnal Ilmiah Pendidikan Khusus),

http://ejournal.unp.ac.id/index.php/jupekhu

Volume 1 Nomor 3 September 2012

Iwan Kurniawan (2015). Implementasi Pendidikan Bagi Siswa Tunanetra Di Sekolah Dasar Inklusi. Edukasi Islami Jurnal Pendidikan Islam Vol. 04, Juli 2015

Kirk, S., Gallagher, J. J., Coleman, M. R., \& Anastasiow, N. (2009). Children Who Are Deaf or Hard of Hearing. In Educating Exeptional Children.

Lamichhane, K. 2015. "Disability and Barriers to Education" In Disability, Education and Employment in Developing Countries: From Charity to Investment, 212-219. Cambridge: Cambridge University Press.

Milles, \& Huberman. (2013). Qualitative Data Analysis: A Methods Sourcebook. Los Angeles: SAGE Publications.

Moleong, L. (2017). Metodologi Penelitian Kualitatif. Bandung: PT Remaja Rosdakarya. Dipetik September 27, 2020.

Sugiyono. (2018). Metode Penelitian : Kuantitatif, Kualitatif, dan $R \& D$. Bandung: Alfabeta. Dipetik September 28, 2020.

UNESCO. 2015. "World Education Forum 2015." Accessed september 7, 2020. http://en.unesco.org/world-educationforum2015/incheon-declaration. 